\title{
Gran historia como historia ambiental
}

\author{
Alfred W. Crosby* \\ UNIVERSIDAD DE TEXAS EN AUSTÍN
}

El texto es una demostración de "macrohistoria ambiental", en continuidad con el libro The Columbian Exchange publicado hace 40 años. Y para resolver mejor las preguntas se remonta hasta unos 50,000 años, con la llegada de los primeros humanos a lo que será el continente americano, donde desarrollaron sistemas agrícolas variados, y en algunos aspectos superiores a los del Viejo Mundo (mandioca, papa, maíz). Una hectárea de papa, con un poco de leche, permite la supervivencia de toda una familia. Hasta algunas debilidades tienen su contraparte: la ausencia de animales domésticos apartó al Nuevo Mundo de ciertas enfermedades. Pero esto fue causa de una fragilidad fatal después de 1492 , origen de un colapso humano.

(Intercambio colombino, mandioca, maíz, papa, epidemias, domesticación)

\footnotetext{
oy historiador ambiental, estudioso de la interacción entre la humanidad y el medio ambiente. Dentro de esta categoría soy un macrohistoriador, practicante de la "Gran historia", un tipo de historiografía que aprovecha no sólo la evidencia primaria documental -diarios, memorias, informes diplomáticos, etcéterasino también, y especialmente, la evidencia científica. Respecto del valor de este acercamiento, me alineo con David Christian: "Conforme se amplía el marco a través del cual observamos el pasado, aspectos del pasaje histórico que fueron alguna vez demasiado grandes para caber pueden verse en su totalidad". ${ }^{1}$ Aquí, voy a ensayar

*crosbyaw@comcast.net

${ }^{1}$ David Christian, Maps of Time: An Introduction to Big History, Berkeley, University of California Press, 2004, 8.
} 
con ustedes algo de la macrohistoria ambiental mediante el examen de algunos elementos y tendencias que son tan amplios que quizá hayan pasado desapercibidos.

Éste es mi segundo intento de elaborar un análisis formal de las correspondencias, fallas, mezclas y choques de los ecosistemas primordiales de los dos más importantes conjuntos geográficos para el Homo sapiens: el Viejo Mundo (Euroasia y África) y el Nuevo Mundo (las Américas). Publiqué mi primer ensayo en The Columbian Exchange, hace ya cuarenta años, ${ }^{2}$ pero datos pertinentes que no noté entonces ahora me persiguen, al igual que mis tardías reacciones a unas observaciones del más prominente naturalista occidental del siglo XVIII, Georges-Louis Leclerc, el conde de Buffón, autor de los influyentes 44 tomos de la Histoire naturelle.

Buffón estaba convencido que los animales del Nuevo Mundo eran inferiores a los del Viejo por ser más pequeños, más lentos, menos inteligentes, etcétera. "Ningún animal americano," escribió, "puede compararse con el elefante, el rinoceronte, el hipopótamo, el dromedario, la jirafa, el búfalo, el león, el tigre, etcétera”. Estaba igualmente seguro que los amerindios también eran inferiores a sus homólogos del Viejo Mundo: físicamente débiles, de sentidos poco agudos, con órganos reproductivos pequeños y un débil ardor sexual. ${ }^{3}$

La "teoría de la degeneración americana" de Buffón estaba imperfecta y hasta venenosa, pero algunos de los datos duros que propició su defectuosa teorización no pueden ser descartados sumariamente. ¿Por qué en realidad no hay leones, elefantes, rinocerontes y animales similares en América? ¿YY por qué las poblaciones amerindias se disminuyeron tan precipitadamente en el tiempo de Bufón?

Para comenzar nuestra respuesta sobre la ausencia de megafauna y el eventual colapso de la población humana regresemos unos cien mil ańos, cuando miembros de la especie Homo sapiens emigraron

${ }^{2}$ Alfred W. Crosby, The Columbian Exchange: Biological and Cultural Conseequences of 1492, Westport, Praeger Publishers, 2003. Traducido al espańol, El intercambio colombino, México, unam, 1992.

${ }^{3}$ http:www.ansp.org/Jefferson/otherPages/degeneracy-1.php; Richard Conniff, "All-American Monsters", Smithsonian, abril, vols. 41, 42, 2010, 
de África para, después de unos 50,000 años, establecerse como la especie de megafauna terrestre más ampliamente dispersa (perdón por la jerga: "megafauna" se refiere a animales con peso adulto mínimo de cien libras [ 45 kilos]). Algunos milenios después (los paleontólogos no han concordado con la cantidad exacta), algunos humanos (que podemos llamar ahora "amerindios") cruzaron el estrecho de Bering (Beringia cuando está seco), el umbral del más grande premio territorial del sistema solar que quedaba abierto a la explotación humana; dos continentes con una extensión de unos dieciséis millones de millas cuadradas. Esos tempranos amerindios fueron los primeros de su especie en llegar al Nuevo Mundo, tierra sin humanoides, homínidos, neandertales, Homo erecti, y sus primos, los chimpancés, gorilas y orangutanes.

El desafío para esos colonos amerindios consistió en adaptarse al medio ambiente de ese mundo o ajustarlo activamente a ellos. Desarrollaron su propia técnica agrícola y domesticaron buen número de nuestras más valiosas plantas comestibles: maíz, papa, camote, mandioca, varias leguminosos (frijoles, habas, judías, alubias, y habichuelas, entre otros), tomate, cacahuate, chilacayote, calabaza, papaya, guayaba, aguacate, pińa, chile, cacao y muchos otros, ${ }^{4}$ sin las cuales el surgimiento de la civilización moderna habría sido muy difícil.

En general, los cultivos del Nuevo Mundo son más ricos calóricamente que los del Viejo Mundo, y ofrecen potencialmente mayor productividad en más variedades de suelo y clima; aunque anunciar este tipo de comparación abstracta a menudo carece de valor práctico. En todo caso, lo importante no es el contraste entre los cultivos de esos dos mundo per se, sino el hecho que el agricultor que tuviera acceso a ambos grupos ha mostrado mayores probabilidades de sobrevivir y reproducirse, comparado con aquel que sólo tuviera acceso a uno. La moraleja aquí es que el principio que rige a la agricultura es similar al del jugador: "Cubre tus apuestas".

${ }^{4}$ Sucheta Mazumdar, "The Impact of New World Food Crops on the Diet and Economy of China and India, 1600-1900”, en Raymond Grew, ed., Food in Global History, Boulder, Westview Press, 1999, 58-74. 
El espacio no permite emprender un examen, por breve que fuera, de todas -o muchas- de las plantas comestibles americanas enumeradas arriba, así que he escogido a tres que son, junto con el trigo y el arroz del Viejo Mundo, algunos de los cultivos más esenciales para la supervivencia humana: mandioca, maíz y la papa blanca (conocida como la papa irlandesa).

La mandioca (o tapioca) es un cultivo básico y generoso que muchas personas tal vez no conocen porque se cultiva y consume casi exclusivamente en los trópicos. Sin embargo, no debemos dejarlo pasar por alto porque entre latitud de 30 grados norte y 30 grados sur, y desde el nivel de mar hasta dos mil metros de altura, es uno de los alimentos básicos de la población.

La mandioca es apreciada principalmente por sus nutritivas raíces, y menos por la cantidad o las cualidades de sus hojas. Produce escasas cantidades de vitaminas, proteínas y hierro, pero abundantes carbohidratos. Es una de nuestras más ricas fuentes de calorías, rebasando al trigo y al maíz. Otro beneficio es que es una planta robusta que prospera aun en suelos pobres, y que se recupera rápidamente de los azotes de enfermedades y plagas así como de sequías o del drenaje inadecuado.

En estado crudo, la mayoría de las especies de mandioca son tóxicas, pero es fácil eliminar las sustancias dañinas. Una vez cosechada, la mandioca se pudre rápidamente pero -afortunadamentelas raíces que permanecen en el suelo pueden retener su valor nutritivo por varios años. La mandioca es un alimento clásico de los pobres, elemento que hoy no puede faltar en la dieta de unos ochocientos millones de personas, la mayoría en Nigeria, la República Democrática del Congo, Brasil, Indonesia y Tailandia.

Los portugueses (los distribuidores transoceánicos de prácticas humanas más subestimados de la historia) llevaron la mandioca desde su tierra de origen, Brasil, a través de los océanos hasta las zonas tropicales del Viejo Mundo, de manera que para 1558 se estaba cultivando a lo largo del río Congo. ${ }^{5}$

5 Jason Clay, World Agriculture: A Commodity-by-Commodity Guide to Impacts and Practices, Washington, Island Press, 2004, 447-461; Nagib Nassar y Rodomiro Ortiz, "Breeding Cassava to Feed the Poor", Scientific American, vol. 302, mayo 2010, 78-84. 
El maíz, por su parte, es un cereal, pero en contraste con otros granos, como el trigo, el centeno, la cebada y la avena, poco se parece a sus ancestros. Presenta sus semillas al mundo en la forma de mazorcas, múltiples filas de granos envueltas en varias capas de hojas. Es incapaz de sembrarse solo de manera eficiente ni de sobrevivir independientemente. Precisa de un auxiliar-como tú o yo-que abra la envoltura, desgrane la mazorca y siembre los granos. De otro modo, las semillas se ahogan dentro de su envoltura o, si las hojas de alguna manera logran abrirse, sólo caerán en montón en un estrecho lugar del suelo donde brotarán para morir pronto.

En al menos un sentido, resulta ventajosa la envoltura de la mazorca, pues protege los granos de pájaros, ardillas y otras amenazas. Otra cualidad positiva del maíz como cultivo es que es una excelente fuente alimenticia, incluso cuando las circunstancias dictan que se coseche en estado verde. Además, si ya pasó el momento propicio para cosecharlo porque el campesino está ocupado en otros andares -un huracán, una guerra o lo que fuere- los granos viejos pueden permanecer en la mazorca sin riesgo por largo tiempo, hasta que la crisis haya pasado. Y aún cosechados, si la crisis resurge, los granos secos pueden almacenarse por meses, o años, sin que se deterioren.

El maíz, además, prospera en un rango amplio de suelos y regímenes de precipitación. Para 1492, se cultivaba en Norte y Sur América, entre 58 grados norte y 40 grados sur. Hoy, es el cereal más sembrado, geográficamente hablando, en el mundo, y es uno de los más importantes alimentos básicos de la humanidad. ${ }^{6}$

Gracias a sus orígenes tropicales y semitropicales en las Américas, el maíz estaba preadaptado a los suelos y climas del sur de Europa, donde para 1500 algunos ibéricos lo cultivaban. Allí, llegó a establecerse como un cultivo estándar en el siglo Xvi, y lo mismo ocurrió en el sur de Francia en el siglo siguiente. Para el siglo xviII, el cultivo del maíz se extendió al norte de Italia y los Balcanes, y poco después entró en el sur de Rusia. En el siglo xIx, el cultivo del maíz era importante en regiones occidentales del Adriático y aún más hacia el Oriente. 
Los portugueses fueron los principales responsables de introducir tempranamente el maíz y otros cultivos amerindios en las provincias costeras de China en el siglo xvi. Desde allí, su cultivo se extendió tierra adentro, donde llegó a ser la cosecha más destacada en algunas regiones. En una obra geográfica local de la provincia de Jiangsi leemos que "El principal cultivo en las colinas y montańas [...] es el maíz [...] que provee la mitad del alimento anual para los habitantes de la montaña [...] Por lo general, se cultiva maíz en el lado asoleado de las laderas [y] camote [otra planta comestible amerindia] en el lado sombreado"?

Es probable también que los portugueses introdujeran el maíz, esa planta del Nuevo Mundo, en la India, donde para 1800 estaba ampliamente distribuido, como botana en su mayoría, aunque en las provincias más pobres, como las tierras altas de los Himalayas, era un alimento básico. Para esas fechas, el maíz, aparte de ser uno de los alimentos principales de los habitantes del Nuevo Mundo desde siglos atrás, ahora llevaba siéndolo dos siglos en todo el mundo.

En el 2000, la producción mundial de maíz fue de 593 millones de toneladas métricas. Entre los principales productores están Estados Unidos, China, India, Indonesia y Sudáfrica. En el primero, se utiliza comúnmente como alimento para el ganado, para propósitos industriales y para el consumo humano. En las otras naciones mencionadas, donde no existía una sola planta de maíz en 1492, ahora es una de las bases de la dieta humana. ${ }^{8}$

El tercer cultivo alimenticio que seleccioné para su análisis no podría ser otro que la papa blanca, un legado de los incas a la humanidad. Los antepasados de mi madre fueron migrantes irlandeses que hace siglo y medio huyeron de la gran hambruna. En tiempos precolombinos, la papa era totalmente desconocida en el Viejo Mundo y, de hecho, también en América del Norte adonde, al parecer, fue llevada por colonos escoceses-irlandeses en el siglo XviII. El origen de su cultivo nos lleva atrás hasta los pioneros agricultores

7 Sucheta Mazumdar, "Impact of New World Food Crops", en Food in Global History, 69.

${ }^{8}$ Jason Clay, "Maize" World Agriculture and the Environment, Washington, Island Press, 2004, 407-428. 
amerindios del área alrededor del lago Titicaca, a elevaciones arriba de la zona donde prosperaba el maíz. Mucho antes de 1492 era un cultivo común desde Venezuela hasta Argentina.

Las ventajas de la papa fueron, y son, muchas. Aunque para sembrarla no se requiere de más equipo que una sencilla y barata estaca, produce grandes cantidades de alimento en una variedad amplia de suelos y climas. Cualitativamente, no es tan nutritiva como el trigo, por ejemplo, pero provee más nutrientes que la mayoría de los granos, y es asombrosamente rica en calorías. Produce más combustible crudo para mantener al cuerpo activo que casi cualquier otro cultivo. Una hectárea de papa adicionada con un poco de leche mantendrá activa a una familia campesina, al menos lo suficiente como para regresar al campo y sembrar más papa.

Sabemos que para el año de 1539 la papa ya estaba en Europa, llevada allí por los conquistadores españoles. Según los estándares de la cocina europea distaba mucho de ser un alimento ideal, y generaciones de aristócratas la despreciaban, aduciendo que causaba lepra y flatulencia. No obstante, autócratas como Federico el Grande de Prusia y Pedro el Grande de Rusia alentaron su cultivo y consumo porque requerían fuentes nutritivas abundantes, pero baratas, para sus campesinos y soldados. Para las últimas décadas del siglo xIX, se cultivaba desde el Atlántico hasta el interior de Rusia y Ucrania. Antes de esta fecha, la sembraban en la India, mientras que en China se conoce desde tiempos de la dinastía Ming; al menos hacia el año $1600 .^{9}$

Pero sólo hubo una nación del Viejo Mundo donde las masas apostaron sus vidas a la papa: Irlanda. Allí, donde muchas personas comían hasta tres kilos de este tubérculo al día, la población aumentó de unos cuatro millones de habitantes a más de nueve millones entre 1760 y 1841. Pero, en la década de 1840, una plaga (o tizón, phytophthora infestans) proveniente de las Américas, arrasó con los campos de papa en Europa con efectos verdaderamente devastadores en Irlanda. De 1845 a 1851, un millón de irlandeses murieron

${ }^{9}$ Ellen Messer, "Potatoes (White)", The Cambridge World History of Food, vol. 1, Cambridge, Cambridge University Press, 2000, 187-201. 
de hambre y enfermedades asociadas, y quizá otro millón huyó por el mar Irlandés y el océano Atlántico. La gran mayoría fue a Estados Unidos (cabe señalar que esta migración jamás fue mencionada en ninguna clase a la que asistí como alumno un siglo después). ${ }^{10}$ Por cierto, la plaga phytophthora aún existe; gracias a ella el verano pasado en Massachusetts los jitomates que sembró mi esposa adquirieron un color pálido, marrón-amarillento.

Hoy los principales productores de papa son China, que cultiva más que cualquier otra nación ( $12 \%$ del total, según una de mis fuentes, aunque otra dice que es $; 23 \%$ !). Otros grandes productores son la India, Rusia, Ucrania y Estados Unidos. En esos países donde no crecía una sola plantita de papa en 1492, ahora una escasez de este tubérculo constituiría un desastre de grandes proporciones, salvo en Estados Unidos, donde sus consecuencias serían menores.

Ahora pasamos al tema de los amerindios en su papel de domesticadores de animales. Los efectos del inteligente Homo sapiens -con su gran cerebro, su pulgar oponible, etcétera- al irrumpir en el medio ambiente americano fueron enormes. Los amerindios, como ya mencionamos, inventaron la agricultura del hemisferio occidental y todo lo que la acompañaba; es decir, la civilización -si me permiten usar esta etiqueta muy usada- con sólo una modesta contribución de animales domesticados. El único animal de cierto tamaño que llegó con ellos al Nuevo Mundo fue el más antiguo de los compañeros del hombre: el perro. Los amerindios domesticaron pocas criaturas del Nuevo Mundo, y las únicas especies de megafauna fueron la llama y la alpaca. Como fuente de nutrición, ninguna especie de las Américas superó a las del Viejo Mundo; y tampoco servían para montarse, llevar cargas pesadas o jalar un arado.

Pero hubo una importante, aunque no permanente, ventaja de su poca suerte como domesticadores de animales; a saber, no convivieron habitual e íntimamente con animales, ni compartían con ellos sus alimentos y espacios de vivienda como lo hicieron los agricultores del Viejo Mundo, quienes por milenios vivían bajo el mismo

${ }^{10}$ Christine Kinealy, The Geat Calamity: The Irish Famine, 1845-52, Boulder, Gill \& MacMillan, 1985, 168. 
techo que sus animales. Gracias a esto, los amerindios no conjuraron nada que se asemejara al flagelo de enfermedades contagiosas como las que surgieron entre los campesinos del Viejo Mundo debido a su "convivencia" con animales: sarampión, viruela, influenza, varicela, tuberculosis, dengue y fiebre amarilla, entre otras.

Así, los pueblos del Viejo Mundo pagaron un precio alto en víctimas infantiles por esas pestes, a cambio de conseguir la ventaja de que aquellos niños que lograran sobrevivir crecieran para formar una población adulta resistente a esas infecciones. ${ }^{11}$ En cuanto a los amerindios y su vulnerabilidad ante esas infecciones microbianas en el Nuevo Mundo, hubo pocas enfermedades de este tipo que pudieran contraer, aunque podría mencionar al menos la enfermedad de Chagas. Habiendo llegado tarde los amerindios al Nuevo Mundo, los parásitos y gérmenes de esa tierra tuvieron sólo unos pocos milenios para adaptarse a los sistemas inmunes humanos y sus particularidades. Además, en un inicio hubo pocos amerindios y su perfil genético tenía poca variación. Un efecto de esto fue la -digamossimplicidad de su capacidad heredada de combatir infecciones; en otras palabras, su potencial inmunológico.

Mientras todo esto se hervía en el nivel micro, otro fenómeno similar dictaba cambios extremos en el nivel macro. Una de las más ampliamente difundidas revoluciones biológicas que el arribo de los amerindios haya desencadenado (y una, vale decir, en la que muchos de sus descendientes niegan con vehemencia el papel de sus antepasados) tuvo que ver con la extinción de muchas de las especies de megafauna del Nuevo Mundo. Las pérdidas en Norteamérica, donde la variedad de grandes mamíferos en la época de la llegada de los amerindios fue mayor a la del África actual, abarcan 34 especies, entre ellas el mamut, el mastodonte y el perezoso terrestre, entre otras - diez de las cuales tenían peso adulto mayor a una toneladajunto a especies poco propensas a la extinción, como el caballo y el camello. Esos animales habían vivido en Norteamérica por cientos de miles, quizá millones, de años, pero para 10,000 a. C. todos ha-

${ }^{11}$ Ann Ramenofsky, “Diseases of the Americas, 1492-1700", en The Cambridge World History of Human Disease, Cambridge, Cambridge University Press, 1993, 323. 
bían desaparecido. Buffón atribuyó su desvanecimiento a la intrínseca inferioridad de esa megafauna, hecho que atribuyó al clima templado y húmedo de su hábitat (jaunque no trataba el tema del calentamiento global!).

En Sudamérica y Australia, la desaparición de grandes mamíferos fue aún mayor que en América del Norte. Además, numerosas especies de megafauna se extinguieron en el Viejo Mundo, aunque no fueron tantas y su extinción fue menos precipitada. En su conjunto, las extinciones de megafauna en el mundo, en ese periodo, bien podrían constituir la mayor pérdida de formas superiores de vida desde la desaparición de los dinosaurios.

La explicación, de mayor circulación, de las excepcionales grandes pérdidas en el Nuevo Mundo hace unos 12,000 años es una que el conde de Buffón quizá aceptaría. Sostiene que las extinciones ocurrieron en el mismo periodo general (hace unos 12,000 años, apenas un ayer para un geólogo) de la llegada de los amerindios. Por esta razón, muchos paleoantropólogos (Paul S. Martin es el más conocido) atribuyen las desapariciones precisamente a ese début. ${ }^{12}$

La megafauna del Nuevo Mundo no tenía experiencia previa con cazadores humanos, de manera que se podría decir que murieron por ignorancia. Muchos ni siquiera sabían que debían huir de aquellos cazadores, o pelear contra ellos, así que fueron presas fáciles que los cazadores llevaron al umbral de la extinción. En contraste, la megafauna de África y Euroasia (donde un buen número de los gigantescos leones, tigres y elefantes del Pleistoceno aún viven en nuestros días) había compartido su ecosistema con homínidos y humanos desde tiempos inmemoriales y habían aprendido cómo sobrevivir a sus depredaciones.

Muchos expertos dudan que unos pocos miles, o decenas de miles, de cazadores equipados con tecnologías cavernícolas pudieran haber eliminado a millones de mamuts, rinocerontes lanudos, perezosos terrestres, bisontes gigantes y caballos americanos, aunque es cierto que los animales grandes suelen tener índices reproductivos muy

${ }^{12}$ Paul S. Martin, Twilight of the Mamnmoths: Ice Age Extinctions and the Rewilding of North America, Berkeley, University of California Press, 2005. 
bajos. En lo personal, puedo imaginar que si los cazadores mataban a algunos animales más de cada especie de megafauna que los que nacían, y si lo hicieron durante docenas de generaciones, sí es posible que hayan extinguido a especies enteras; ${ }^{13}$ pero es sólo un supuesto. Los escépticos de la teoría de la proeza de los cazadores echan la culpa por las extinciones a otras causas; por ejemplo, a las enfermedades que los amerindios trajeron desde Asia, al impacto de un cometa (como lo que ocurrió con los dinosaurios), o al cambio climático. Aunque me parece más factible esta última hipótesis, el hecho es que hubo episodios de cambio climático en épocas anteriores y nunca causaron extinciones masivas de megafauna; así que, ¿por qué habría sido diferente esa vez?

Permítanme especular un momento: pensemos que el arribo de los cazadores amerindios coincidió con alguna de las varias épocas de cambio climático de ese periodo. En ese escenario, la llegada de los cazadores habría constituido una crisis para la megafauna y el cambio climático otra, y las dos juntas bien pudieran haber desencadenado una catástrofe lo suficientemente severa como para eliminar especies enteras; pero es otra conjetura.

La teoría de los cazadores ha atraído la atención de investigadores que pretenden atribuir los fuertes contrastes entre el ganado domesticado de los pueblos del Viejo y Nuevo Mundo frente al impacto humano. ¿Por qué los amerindios nunca domesticaron especies de megafauna con el éxito que vemos en los pueblos del Viejo Mundo: caballos, reses, ovejas, cabras, cerdos, el búfalo de agua, etcétera? Una respuesta común, pero fácil, sostiene lo siguiente: fue porque hubo en las Américas muy pocas especies de megafauna potencialmente domesticables.

Esta especulación provee una hipótesis que explica por qué nuestro caballo -que evolucionó primero en Norteamérica para luego

${ }^{13}$ Christopher Johnson, "Megafaunal Decline and Fall”, Science, vol. 326, 20 noviembre 2009, 1072-1073; Jacquelyn L. Gill et al., "Pleistocene Megafaunal Collapse, Novel Plant Communities, and Enhanced Fire Regimes in North America”, Science, vol. 326, 20 noviembre 2009, 1100-1103; Charles Q. Choi, "Lost Giants: Did Mammoths Vanish before, during and after Humans Arrived?", Scientific American, vol. 302, febrero 2010, 21-22. 
migrar al Viejo Mundo- se desvaneció de su lugar de origen y no volvió a aparecer allí hasta que los humanos del Viejo Mundo lo descargaron de sus naves después de $1492 .{ }^{14}$ (Vale notar que al retornar a su medio ambiente original en las Américas, los caballos solían volverse silvestres y propagarse para formar grandes hatos, lo que ha dado lugar a propuestas serias sobre el posible restablecimiento del elefante en la biósfera americana (¡imaginemos enormes grupos de elefantes silvestres merodeando por la UNAM!).

El debate sobre la extinción de tantas especies de megafauna hace 10,000-15,000 años sigue acalorado; pero no lo podemos resolver aquí, no tenemos que hacerlo, y no sería posible. El hecho es que su desaparición simplificó los ecosistemas del Nuevo Mundo y abrió las puertas a invasiones de especies alienígenas. Algunos de esos invasores lograron establecerse como especies claves en regiones enteras: un ejemplo es el ganado en las pampas y grandes llanos. Félix de Azara, un sano, respetable soldado, ingeniero y naturalista de finales del siglo xviII, calculó que el número de ganado silvestre en Sudamérica entre 26 grados y 41 grados sur (la extensión de las pampas) llegó en 1700 a un máximo de unos cuarenta y ocho millones de cabezas. ${ }^{15}$

La migración precolombina de los amerindios del Viejo al Nuevo Mundo a través de Beringia fue el más espectacular capítulo en la historia de la migración humana por muy largo tiempo. Aunque su travesía fue, literalmente, a pie, en esa época otros humanos estaban aprendiendo a navegar. Así, para comienzos del siglo xv, Zheng $\mathrm{He}$ y los chinos ya enviaban flotillas al África oriental, aunque al regresar se quedaron nuevamente en casa. Esta decisión permitió a los navegantes europeos de fines del siglo XV -y hasta el XIX-arrebatar el título como los campeones de travesías oceánicas en naves. Hasta hoy seguimos experimentando las repercusiones de sus hazańas.

${ }^{14}$ Jens Lorenz Franzen, The Rise of Horses, trad. de Kirsten M. Brown, Baltimore, Johns Hopkins University Pess, 2010, 182.

${ }^{15}$ Felis de Azara, The Natural History of Paraguay and the River La Plata, vol. I, Edinburgh, Adam and Charles Black, 1838, 63; James W. Corbett et al., "Late Pleistocene Extinctions," Science, vol. 189, 1 junio 1973, 905; véase Alfred W. Crosby, The Columbian Exchange: Biological and Cultural Consequences of 1492, Westport, Praeger, 2003, 86-97. 
Los marineros, exploradores y colonos europeos llegaron al Nuevo Mundo en naves de vela, con espadas de metal, armas de fuego, pólvora y ganado, especialmente caballos. Todo ese equipaje fue muy superior a lo que los pueblos amerindios pudieran reunir; y en esos mismos barcos los europeos trajeron a su más fiel aliado: varias infecciones epidémicas desconocidas en el Nuevo Mundo.

La historia de la mayoría - quizá todas- de las colonias europeas en el Nuevo Mundo comenzó con las terribles epidemias que tan drásticamente socavaron la capacidad de los pueblos locales de combatir a los invasores. ${ }^{16}$ Permítanme seleccionar un ejemplo tomado de la documentación asociada con mis propios antecedentes - por ser ciudadano del estado de Massachusetts- uno que aparece en la historia de los libros de texto con el establecimiento de Plymouth en 1620. En 1616, y dos veces más en los años siguientes, una nueva peste arrasó con las villas indígenas de aquella zona costera, dejándolas prácticamente abandonadas. Thomas Dermer, un testigo europeo, reportó ver pueblos recientemente "muy poblados [pero] ahora totalmente vacíos; en otros lugares permanecían unos remanentes, pero ninguno libre de enfermedad". En 1621, una partida de colonos de Plymouth se aventuró tierra adentro, caminando entre villas abandonadas y campos de maíz donde el zacate rebasaba sus cabezas. Un inglés recordó que "Miles de hombres vivían allí [pero] hace poco murieron en una gran plaga: y lástima era, y es, ver tantos campos buenos, tan bien atendidos, pero sin hombres para cuidar y abonarlos". Cerca de la bahía de Boston, Thomas Morton vio "un lugar habitado por muchos [donde] queda sólo un hombre vivo para contar lo que sucedió al resto; (al parecer) los vivos no bastan para enterrar a los muertos, quienes quedan como carroña para los cuervos, buitres y otras alimañas". ${ }^{17}$

Los colonos europeos se fijaron en, y alentaron, esas intervenciones de un dios racista. Morton recordó una frase del libro del Éxodo:

${ }^{16}$ Noble David Cook, Born to Die: Disease and New World Conquest, 1492-1650, Cambridge, Cambridge University Press, 1998.

${ }^{17}$ Alfred W. Crosby, "God...Would Destroy Them, and Give Their Country to Another People”, American Heritage, vol. 29, octubre-noviembre 1978, 38-43. 
"Poco a poco (decía Dios a su pueblo desde antiguo) los expulsaré de enfrente de Ustedes para que se multipliquen y hereden la tierra". ${ }^{18}$

Para aquellos lectores que encuentran esos cuentos epidemiológicos de horror demasiado estrafalarios, demasiado "ciencia-ficciosos" para ser aceptados, sugiero que ponderen nuestra actual experiencia con el sida, una infección venérea que va extendiéndose constantemente a pesar de nuestros más valientes esfuerzos. ¡Ahora, imagínense que fuera una enfermedad transmitida por el aire, como la influenza!

Los tempranos contactos entre el Nuevo y Viejo Mundo a través de los humanos en sus fronteras pudieron haber coincidido con horrendos índices de mortalidad de ciertas criaturas. De hecho, conocemos casos en que precisamente eso sucedió; algunos ejemplos podrían ser la megafauna hace varios miles de ańos, y los mismos amerindios hace tan sólo unos pocos siglos (en algunos casos, unas cuantas décadas). Pero esto es sólo la mitad de la historia.

La otra mitad no tiene que ver con un decremento, sino con un desenfrenado incremento: el del número de amerindios originales, aquellos asiáticos precolombinos que cruzaron al Nuevo Mundo para ocuparlo miles de años atrás. Sabemos muy poco de los detalles de aquel increíble viaje, más allá del hecho que tuvo que haber ocurrido. Hace 25,000 años (quizá menos), no existían humanos en el Nuevo Mundo. Luego, los primeros -estimamos que fueron unos cuantos miles de cazadores-recolectores en cada siglo- migraron al Nuevo Mundo a través de Alaska. A lo largo de varias generaciones los descendientes de esos pioneros se extendieron hacia el oriente y sur, pasando por territorios vírgenes hasta llegar a Tierra de Fuego. Aunque al principio fueron, sin duda, muy pocos, y a pesar de su breve residencia en ese mundo (a lo mucho unos cuantos milenios), para 1492 sumaban millones. ${ }^{19}$

En esa fecha, algunos seguían viviendo como cazadores-recolectores, pero muchos otros -que ya dependían de la agricultura, o

${ }^{18}$ Alfred W. Crosby, "Virgin Soul Epidemics as a Factor in the Aboriginal Depopulation of America", en Germs, Seeds, and Animals: Studies in Ecological History, Armonk, M. E. Sharpe, 1994, 97-108.

${ }^{19}$ Suzanne Austin Alchon, A Pest in the Land: New World Epidemics in Global Perspective, Albuquerque, University of New Mexico Press, 2003, 170-73. 
vivían en latitudes tropicales y regiones adjuntas- habían alcanzado densidades demográficas comparables a los del Viejo Mundo. Esos amerindios no eran como Hollywood los representa: montados a caballo y encerrando a los vaqueros en medio de gritos de "; Wahoo wah?" No, eran pueblos con magníficos edificios religiosos, nacientes sistemas de escritura, complejos gobiernos y grandes ciudades.

Si su evolución desde la cacería y recolección a la "civilización" (perdón, pero no se me ocurre de momento una palabra mejor: portemanteau ${ }^{20}$ hubiera ocurrido en el Viejo Mundo, las narrativas y análisis de sus primeros milenios en el Nuevo Mundo ocuparían libros enteros; no, más bien... salas enteras de nuestras bibliotecas. Pero no fue así; sucedió sin testigos oculares del Viejo Mundo y, por esta razón, ha escapado a la atención de la mayoría de los académicos y científicos, salvo la de los arqueólogos, a quienes sólo les prestamos atención cuando nos cuentan algo que nos parece provocador, como el canibalismo.

Contactos a través del Atlántico, no por el estrecho de Bering, desencadenaron un segundo disparo demográfico en el Nuevo Mundo. En los primeros siglos postcolombinos fueron modestos los números y las tasas de crecimiento de los colonos que dejaron el Viejo Mundo para pasar al Nuevo. Después -el inicio del siglo XVIII parece una fecha razonable- las poblaciones coloniales comenzaron a multiplicarse rápidamente; primero los colonos europeos en la templada zona norte y, más tarde y a una tasa menor, los esclavos africanos.

¿Qué fue lo que persuadió a los colonos europeos a participar en esa extravagancia demográfica? Cito a Benjamín Franklin, mi norteamericano favorito de la época colonial y revolucionaria. Anticipando por medio siglo a Thomas Malthus, en 1751 Franklin publicó su ensayo "Observations concerning the Increase of Mankind, Peopling of Countries, \& c.". (Observaciones concernientes al aumento de la humanidad, el poblamiento de los países, etcétera).

${ }^{20}$ En francés en el texto: perchero. 
Siendo así de abundante la tierra en América [la deserción debida en buena medida a las pérdidas de amerindios por infecciones importadas], y tan barata que un Hombre labrador [blanco, por supuesto] que entiende la Agricultura puede en corto Tiempo ahorrar suficiente Dinero para comprar una parcela de tierra virgen suficiente para una Plantación, donde podrá sostener a una Familia; de tal manera que no teme casarse; porque si se atreve a ver hacia el futuro y contemplar cómo sus Hijos, al crecer, obtendrán su sustento, verá que hay más tierra que podrá adquirir a Precios igualmente accesibles, considerando todas las Circunstancias. ${ }^{21}$

El más poderoso motivo que impulsó a los perpetradores de la primera y más antigua intrusión de los antiguos amerindios como, miles de años después, a los de la segunda, la de los granjeros europeos y sus asociados -esclavos, comerciantes, pescadores, etcéterafue la ambición de explotar el riquísimo medio ambiente que se abría ante sus ojos en extensiones de tamańo continental, y allí multiplicarse. En el caso de los amerindios, no existían competidores humanos que se opusieran a sus depredaciones. En el segundo, la población amerindia que vivía en los territorios fue en franco descenso al disminuir por el azote de los microbios y trastornos que los exploradores y los colonos trajeron desde el Viejo Mundo.

Así termina mi intento de presentar una muestra de la Gran historia medioambiental. Tal vez no sea una obra maestra, pero basta para resaltar algunos de los factores que demandan un nuevo o nuevos tipos de historia. Recomienda, por ejemplo, que expandamos y rearmemos nuestro aprecio del espacio y tiempo. ¿De qué otra manera podremos evaluar la importancia de la desaparición del elefante del Nuevo Mundo? ¿Cómo explicar más la inefectiva resistencia de los amerindios ante los invasores europeos?, o elucidar

${ }^{21}$ Leonard W. Labaree, ed., The Papers of Benjamin Franklin, vol. 4, New Haven, Yale University Press, 1961, 228. "Land being thus plenty in America [the vacancy in large part due to the Amerindian losses to imported infection], and so cheap as that a labouring Man [a white one, of course], that understanding Husbandry, can in a short Time save Money enough to purchase a piece of new land sufficient for a Plantation, whereon he may subsist a Family; such are not afraid to marry; for if they even look far enough forward to consider how their Children when grown up are to be provided for, they see that more Land is to be had at Rates equally easy, all Circumstances considered". 
¿cómo fue posible que Nelson Mandela haya fundado una nación, mientras que el jefe Pontiac de los ottawás no?

Recomiendo agregar a nuestra jerga historiográfica una versión del término acuñado por el químico Premio Nobel, Paul Crutzen, para designar el periodo moderno, llamándolo el Antropoceno: i.e., la época cuando el Homo sapiens constituye la especie clave. Durante los primeros milenios del Antropoceno, nosotros los humanos hemos ocupado, o al menos visitado, toda la superficie terrestre del planeta, amplias extensiones de los océanos, y hasta la atmósfera; hemos arrasado con las junglas, derretido los glaciares y eliminado y enterrado, junto a nuestros templos y basureros, multitudinarias formas de vida. Nuestra especie ha sido una de las causantes más poderosas de las extinciones de otras especies, ha presidido la dispersión de varias y, en algunos casos, el desarrollo de nuevas especies, especialmente formas microscópicas de vida. La sociedad emplea a poetas y dramaturgos para celebrar y vituperar los hechos de la guerra: ¿por qué, entonces, no debería la sociedad utilizarnos para hacer lo mismo para todo aquello que la humanidad ha estado perpetrando contra el ambiente físico durante el Antropoceno?

\section{BIBLIOGRAFÍA}

Alchon, Suzanne Austin, A Pest in the Land: New World Epidemics in Global Perspective, Albuquerque, University of New Mexico Press, 2003, 170-173.

Azara, Felis de, The Natural History of Paraguay and the River La Plata, vol. I, Edinburgh, Adam and Charles Black, 1838, 63.

Chor, Charles Q., "Lost Giants: Did Mammoths Vanish Before, during and after Humans Arrived?", Scientific American, vol. 302, febrero 2010, 21-22.

Christian, David, Maps of Time: An Introduction to Big History, Berkeley, University of California Press, 2004, 8.

ClaY, Jason, World Agriculture: A Commodity-by-Commodity Guide to Impacts and Practices, Washington, Island Press, 2004, 447-461. , "Maize" World Agriculture and the Environment, Washington, Island Press, 2004, 407-428. 
Conniff, Richard, "All-American Monsters”, Smithsonian, abril, vols. 41, 42, 2010.

Cook, Noble David, Born to Die: Disease and New World Conquest, 1492-1650, Cambridge, Cambridge University Press, 1998.

Corbett, James W., et al., "Late Pleistocene Extinctions," Science, vol. 189, 1 junio 1973, 905.

Crosby, Alfred W., "God... Would Destroy Them, and Give Their Country to Another People", American Heritage, vol. 29, octubre-noviembre 1978, 38-43.

, "Virgin Soul Epidemics as a Factor in the Aboriginal Depopulation of America", en Germs, Seeds, and Animals: Studies in Ecological History, Armonk, M. E. Sharpe, 1994, 97-108.

, The Columbian Exchange: Biological and Cultural Consequences of 1492, Westport, Praeger, 2003, 86-97.

Franzen, Jens Lorenz, The Rise of Horses, trad. de Kirsten M. Brown, Baltimore, Johns Hopkins University Press, 2010, 182. Gill, Jacquelyn L. et al, "Pleistocene Megafaunal Collapse, Novel Plant Communities, and Enhanced Fire Regimes in North America", Science, vol. 326, 20 noviembre 2009, 1100-1103.

Johnson, Christopher, "Megafaunal Decline and Fall", Science, vol. 326, 20 noviembre 2009, 1072-1073.

Kinealy, Christine, The Geat Calamity: The Irish Famine, 1845-52, Boulder, Gill \& MacMillan, 1985, 168.

Labaree, Leonard W., ed., The Papers of Benjamin Franklin, vol. 4, New Haven, Yale University Press, 1961, 228.

Martin, Paul S., Twilight of the Mamnmoths: Ice Age Extinctions and the Rewilding of North America, Berkeley, University of California Press, 2005.

Mazumdar, Sucheta, "The Impact of New World Food Crops on the Diet and Economy of China and India, 1600-1900", en Raymond Grew, ed., Food in Global History, Boulder, Westview Press, 1999, 58-74.

Messer, Ellen, "Potatoes (White)", The Cambridge World History of Food, vol. 1, Cambridge, Cambridge University Press, 2000, 187-201.

Nassar, Nagib y Rodomiro Ortiz, "Breeding Cassava to Feed the 
Poor", Scientific American, vol. 302, mayo 2010, 78-84.

Ramenofsky, Ann, "Diseases of the Americas, 1492-1700", en The Cambridge World History of Human Disease, Cambridge, Cambridge University Press, 1993, 323.

The Academy of Natural Sciences, Drexel University, http:www.ansp.org/Jefferson/otherPages/degeneracy-1.php

FECHA DE RECEPCIÓN DEL ARTíCULO: 15 de octubre de 2012 FECHA DE RECEPCIÓN DE LA VERSIÓN FINAL: 12 de diciembre de 2012

Traducción del inglés de Paul C. Kersey Johnson 